\title{
PREDICTING THE ELASTIC MODULUS OF JUTE/POLYPROPYLENE COMPOSITES USING MATHEMATICAL MODELLING TECHNIQUES
}

\author{
Muhammad Usman Saram \\ Department of Mechanical Engineering \\ Memorial University of Newfoundland \\ St. John's, NL, Canada \\ musaram@mun.ca
}

\author{
Jianming Yang \\ Department of Mechanical Engineering \\ Memorial University of Newfoundland \\ St. John's, NL, Canada \\ jyang@mun.ca
}

\begin{abstract}
The development of high-performance engineering materials made from natural resources is rising worldwide, because of the renewable and environmental problems. Among various type of natural fibers, jute fibers have been widely exploited over the past few years. This paper presents the evaluation of elastic modulus of jute/polypropylene (PP) composites using mathematical modelling. Composite models namely Rule of mixtures (ROM), Inverse Rule of Mixtures (IROM), Halpin-Tsai (HT) and Bowyer-Bader (BB) will be employed to confirm the experimental data from the available literature. The effect of the fiber loading, fiber size, and fiber orientation will also be discussed within the scope of the studied models.
\end{abstract}

Keywords - polymer composites; jute fiber; elastic modulus; analytical modelling

\section{INTRODUCTION}

Composites reinforced with short fibers have been receiving huge attention because of the advantages they offer such as processing, easy dispersion in the matrix and anisotropy in properties over the last two decades [1-5]. The properties of composites are greatly influenced by the properties of the constituents and their composition, and by their distribution in the matrix and interaction among them [6]. Typical reinforcements are various expensive and non-reliable synthetic fibers like glass, carbon and so on. With the increase in price of petroleum-based fibers and the uncertainties in supply in recent years, it is important to use natural occurring lignocellulosic fibers. Lignocellulosic fibers have low cost, low density, reduced tool wear, good thermal insulation properties, acceptable specific strength, biodegradation ability and recycling ability without affecting the environment [7-9]. Hence, the composites reinforced with natural fibers as filler are becoming increasingly vital as cheap lightweight environment friendly composites [10]. Jute is a promising material among all the reinforcing natural fibers, because it is comparatively inexpensive and commercially available in the required form. However, physical and mechanical properties of jute are highly uneven and depend on the climate growth surroundings, geographical origin and processing methods [5]. It is one of the main vegetal natural fiber and is produced in Bangladesh, Thailand, India and other countries. It contains about $56-64 \%$ of cellulose, $29-25 \%$ of hemicelluloses, $11-14 \%$ of lignin and a small proportion of fats, waxes and pectin [11]. However, jute and traditional jute products are increasingly replaced by artificial fiber and synthetic products, due to its disadvantages, such as it is woody, coarse, comprises great percentage of lignin and also it cannot be spin to fine fabrics and so on. New technologies have been developed for the fabrication of high value jute products so as to overcome the declining market of jute products. Among the several jute products, jute reinforced composites have high potential for broader applications. The simple and cost-effective processing technique for manufacturing jute composites has extremely increased the interest of using jute as reinforcing filler in polymer composites during the last few years [12].

The mechanical properties of fiber-reinforced composites are affected by a number of parameters such as fiber dispersion, fiber orientation, fiber geometry, fiber volume fraction and the interfacial adhesion between fiber and matrix [13-17]. The properties of fibers derived from plant depend on numerous factors such as locality where they are grown, nature of the plant, age of plant, portion of the plant from which they are obtained, extraction techniques and so on. Further, the mechanical properties of fibers of a single batch have rather statistical distribution. To observe the effect of these factors on the elastic modulus of the composite may involve a large number of experiments. It is therefore crucial to find mathematical models for estimating the elastic modulus of jute/PP composites and thus limit the number of experiments. In literature, numerous analytical models and equations have been developed, and selecting the one model is very challenging, if not possible.

The present work deals with modelling the elastic modulus of the jute fiber reinforced polypropylene composites. Mathematical models available in the literature were used for this purpose, and the results were compared with experimental data from the published works. The aim is to investigate the usefulness of the proposed models and to provide the importance of above-mentioned factors when estimating the Young's modulus of the jute/PP composites.

\section{REVIEW OF MiCROMECHANICAL MODELS}

A variety of mathematical models have been developed to effectively predict the elastic properties of short fiber reinforced 
thermoplastics (SFRT). They range from simple models (e.g. rule of mixtures model) to rather complex models, depending on the factors taken into account. The major benefit of mathematical modelling is that it reduces costly and timeconsuming experiments. Based on author's point of view, the most convenient and practical models are discussed in this section. The following notations are used: $E_{c}, E_{m}, E_{f}$ are the tensile moduli of composite, polymer matrix and fiber respectively; $V_{m}, V_{f}$ are the polymer matrix volume fraction and fiber volume fraction respectively.

\section{A. Rule of Mixtures (ROM) Model [18]:}

This is the simplest available model to predict the young's modulus of a composite material. The model works extremely well for composite materials embedded with aligned continuous fibers with the assumption of equal strain in both fiber and matrix. The young's modulus can be calculated by using the ROM equation as follows:

$$
E_{c}=E_{f} V_{f}+E_{m} V_{m}
$$

\section{B. Inverse Rule of Mixtures (IROM) Model [18]:}

The young's modulus can be determined by IROM as follows:

$$
E_{c}=\frac{E_{f} E_{m}}{E_{m} V_{f}+E_{f} V_{m}}
$$

In case of IROM, the stress was assumed to be uniform in both fiber and matrix.

\section{Halpin-Tsai (HT) Model [19]:}

This model has been used by many researchers for predicting the elastic properties of SFRT. According to Halpin-Tsai model, the tensile modulus of the composite is given by:

$$
E_{c}=\frac{E_{m}\left(1+\xi \eta V_{f}\right)}{1-\eta V_{f}}
$$

The parameter $\eta$ can be calculated using the following:

$$
\eta=\frac{\frac{E_{f}}{E_{m}}-1}{\frac{E_{f}}{E_{m}}+\xi}
$$

where $\xi$ is the shape fitting parameter. It depends on the shape of the particle and the modulus being predicted. For fibers with rectangular or circular shape, the value of $\xi$ is given by the following relation:

$$
\xi=2\left(\frac{L}{D}\right)
$$

where $L$ is the length and $D$ is the diameter of the fiber. In (5) as $L \rightarrow 0, \xi \rightarrow 0$ then (3) reduces to IROM equation. However, when $L \rightarrow \infty, \xi \rightarrow \infty$ then the (3) reduces to ROM equation.

\section{Bowyer-Bader (BB) Model [20]:}

According to Bowyer and Bader model, the tensile modulus is demonstrated by the given relation:

$$
E_{c}=E_{m} V_{m}+k_{1} k_{2} E_{f} V_{f}
$$

where $k_{l}$ is the fiber orientation factor, and $k_{2}$ is the fiber length factor. For fibers with $l>l_{c}$,

$$
k_{2}=l-l_{c} / 2 l
$$

For fibers with $l<l_{c}$,

$$
k_{2}=l / 2 l_{c}
$$

where $l$ is the fiber length and $l_{c}$ is the critical fiber length.

\section{VALidation OF Rom, Irom, HT AND Bb Models}

For the present work, experimental data for the jute/PP composites as a function of fiber volume fraction was obtained from the technical literature. This data gathered for the jute/PP composites varied due to the different properties of jute in a single batch, measurement techniques and processing methods for the composite. Table 1 shows the different jute/PP composite systems that were adopted for this work.

\section{RESUlts AND DiscUSSION}

An attempt was made to estimate the elastic modulus data of jute/PP composites that were adopted from technical literature [21], [22], [23], [24] shown in Fig. 1. The models of ROM [18], IROM [18], HT [19], and BB [20] were employed for the predictions of young's modulus. Table 2 depicts the values of parameters that were used in this study.

The predicted values of young's modulus for the above mentioned models are represented in Fig. 1. Fiber orientation factor, $k_{l}$, is different for both random and longitudinal oriented fiber composites. The value of $k_{l}$ adopted for calculations is 0.5 for fibers arranged in random order [25].

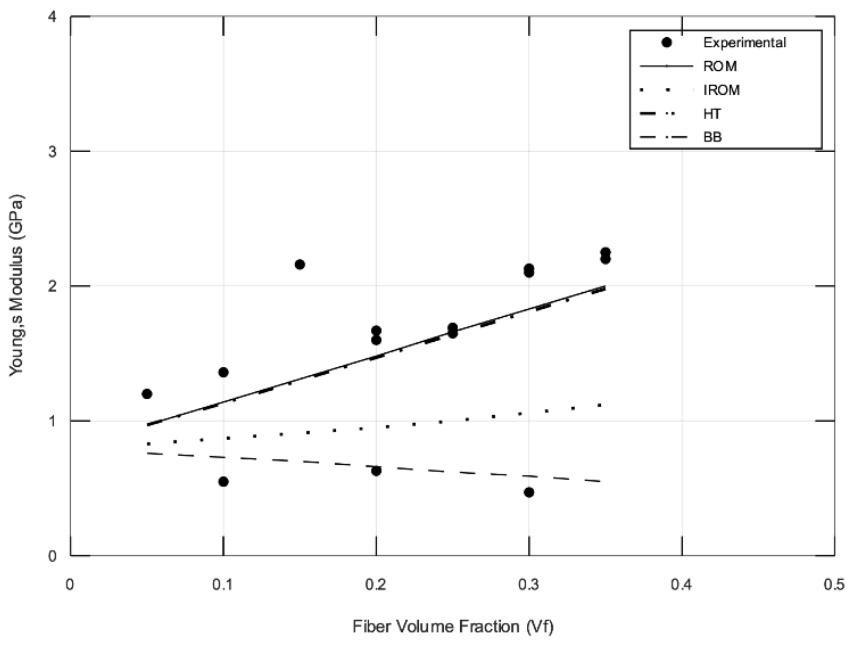

Figure 1. Young's modulus of jute/PP composites adopted from technical literature. 
TABLE 1. SUMMARY OF JUTE/PP COMPOSITE PROPERTIES ADOPTED FROM TECHNICAL LITERATURE AND USED IN THIS STUDY.

\begin{tabular}{|c|c|c|c|c|c|c|c|}
\hline \multicolumn{3}{|c|}{ Jute Properties } & \multicolumn{2}{|c|}{ Polypropylene Properties } & \multirow[b]{2}{*}{$\begin{array}{c}\text { Range of } V_{f} \\
(\%)\end{array}$} & \multirow[b]{2}{*}{ Production Process } & \multirow[b]{2}{*}{ Reference } \\
\hline $\begin{array}{c}E_{f} \\
(G P a)\end{array}$ & $\begin{array}{c}\text { Length } \\
(\mathrm{mm})\end{array}$ & $\begin{array}{c}\text { Aspect } \\
\text { ratio }(L / D)\end{array}$ & $\begin{array}{c}E_{m} \\
(G P a)\end{array}$ & Specific gravity & & & \\
\hline- & 3 & - & 0.78 & - & $0.05-0.15$ & Injection Molding & [21] \\
\hline- & $2-5$ & - & - & - & $0.1-0.3$ & Cold Press & {$[22]$} \\
\hline 4.22 & 0.5 & 75 & 0.8 & $0.9-0.91$ & $0.2-0.35$ & Injection Molding & [23] \\
\hline
\end{tabular}

Fig. 1 denotes that predictions made by ROM model are closer to experimental data than any other models. However, not a good correlation between the experimental and theoretical values of young's modulus predicted by ROM model was observed. This behavior can be explained by the fact that ROM equation is used to describe the tensile modulus of continuous fiber reinforced polymer composites. The ROM model assumes that the fibers are positioned and fully strained along their length. Estimations made by HT model show the similar trend as the ROM model. The HT model is little behind the ROM model in predicting the young's modulus of jute/PP composites shown in Fig. 1. It must be noted that the HT model is relatively comprehensive in the sense that it takes into account various factors such as aspect ratio, size, shape fitting parameter $\xi$ and factor $\eta$. The discrepancies in data occur also due to the relationship of $\xi$ given by (5) was formulated for synthetic fibers with well-defined cylindrical or rectangular cross-sections. Thus, jute fibers with complex cross-sections are evidently not well represented by the relationship established by the HT model.

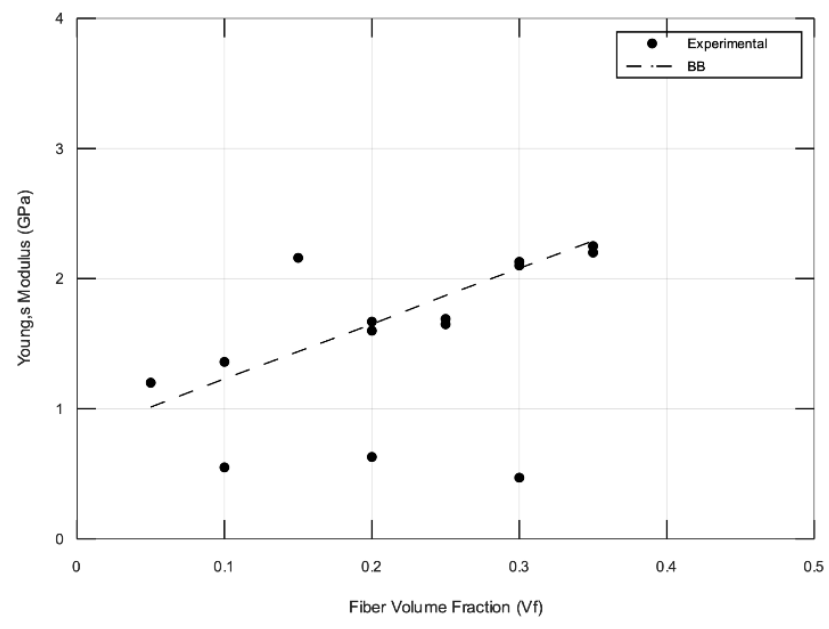

Figure 2. Young's modulus predictions by Bowyer-Bader (BB) model with adjusted parameters, compared with experimental results.

The IROM and BB models underestimate the experimental data from literature. IROM model is normally used to calculate the tensile modulus of continuous fiber reinforced polymer composites. The IROM model assumes that the fiber and matrix are equally stressed. The BB model somehow predicted the composites with lower values of young's modulus with good correlation to the experimental values. Equation (6) of the BB model deals with two factors; fiber orientation factor $k_{1}$, and fiber length factor $k_{2}$. It is however challenging to find the values of $k_{1}$ and $k_{2}$ individually. Some relation is used in technical literature [25] to find the value of $k_{l}$, but the formula merely has some solid theoretical background. The value of $k_{2}$ can be calculated using the (7) or (8); because for $l=l_{c}$, both equations give the same results. Therefore, the values of $k_{1}$ and $k_{2}$ are needed to find them correctly to accurately predicting the experimental data.

An effort was made to adjust the predicted models for the models closest to experimental data, the BB model was identified to have the potential to do so. The new model is the Modified Bowyer-Bader model (MBB) as follows:

$$
E_{c}=E_{m} V_{m}+\alpha E_{f} V_{f}
$$

where $\alpha$ is the overall reinforcing factor and $\alpha=k_{1} k_{2}$. The BB model was modified by adjusting the product $k_{1} k_{2}$ while keeping the other parameters constant, as it is the most sensitive parameter in the model. For $\alpha=1$, the BB model reduces to the ROM model. The parameter $\alpha$ shows that to what extent the young's modulus of the jute fiber contribute to the young's modulus of the composite. The value of $\alpha=1.2$ was implemented, which is higher than the previously assumed value of 0.5 . The modified young's modulus is shown in Fig. 2. The higher value of $\alpha$ implies that either the value of $k_{1}$ or $k_{2}$ is increased, or both are increased. The higher value of $k_{1}$ signifies that the jute fibers are not randomly dispersed but rather aligned. A higher $k_{2}$ indicates that the jute fibers are not short but rather long. For the considered jute fiber volume fraction, these findings reveal that jute fiber length and alignment are crucial for the accurate prediction of tensile modulus of natural fiber reinforced polymer composite as exhibited by adjusting the respective parameters

Table 2. PARAMETERS USED FOR YOUNG'S MODULUS PREDICTIONS.

\begin{tabular}{|c|c|c|}
\hline Parameter & Value & Reference \\
\hline$E_{f}(\mathrm{Gpa})$ & 4.22 & Table 1 \\
\hline$E_{m}(\mathrm{Gpa})$ & 0.8 & Table 1 \\
\hline Aspect ratio $(L / D)$ & 75 & Table 1 \\
\hline Fiber orientation factor $k_{l}$ & 1 & {$[25]$} \\
\hline Fiber length factor $k_{2}$ & 0.5 & {$[25]$} \\
\hline
\end{tabular}


of the BB model.

\section{CONCLUSIONS}

A comparison between experimental results and the predicted values of young's modulus of jute/PP composites has been presented. A set of established micromechanical models and experimental data were selected from the technical literature. All the analytical models shown an increase in young's modulus with increase in volume fraction of jute fibers. The ROM and HT models slightly agree with the experimental data. The ROM model was developed for continuous fiber reinforced polymer composites and is therefore limited in its ability to predict the young's modulus of SFRT. HT model is rather comprehensive and was designed for synthetic fibers with well-define cross-sections. The Bowyer-Bader (BB) and IROM models underestimate the young's modulus of jute/PP composites. For BB model, underestimation is due to the inconsistency in the values of fiber orientation factor and fiber length factor. The IROM model was generally formulated for continuous fiber reinforced polymer composites. Results from BB model could further be improved by adjusting the overall reinforcing factor as it has physical significance. Overall, it was noticed that the parameters related to jute fiber such as fiber length and fiber orientation have a strong effect on young's modulus predictions. Individual young's moduli of jute and polypropylene are less sensitive to predictions.

\section{REFERENCES}

[1] J.-M. Park, S. T. Quang, B.-S. Hwang and K. L. Devries, "Interfacial evaluation of modified Jute and Hemp fibers/polypropylene (PP)maleic anhydride polypropylene copolymers (PP-MAPP) composites using micromechanical technique and nondestructive acoustic emission," Compos. Sci. Technol., vol. 66, pp. 2686-2699, 2006. doi:10.1016/j.compscitech.2006.03.014.

[2] P. Wambua, J. Ivens and I. Verpoest, "Natural fibres: can they replace glass in fibre reinforced plastics?," Compos. Sci. Technol., vol. 63, pp. 1259-1264, 2003. doi:10.1016/S0266-3538(03)00096-4.

[3] A. d. Albuquerque, K. Joseph, L. H. d. Carvalho and J. R. M. Almeidab, "Effect of wettability and ageing conditions on the physical and mechanical properties of uniaxially oriented jute-roving-reinforced polyester composites," Compos. Sci. and Technol., vol. 60, pp. 833844, 2000. doi:10.1016/S0266-3538(99)00188-8.

[4] D. Ray, B. K. Sarkar and N. R. Bose, "Impact fatigue behaviour of vinylester resin matrix composites reinforced with alkali treated jute fibres," Compos. Part A: Appl. Sci. and Manuf., vol. 33, pp. 233-241, 2002. doi:10.1016/S1359-835X(01)00096-3.

[5] T. M. Gowda, A. Naidu and R. Chhaya, "Some mechanical properties of untreated jute fabric-reinforced polyester composites," Compos. Part A: Appl. Sci. and Manufacturing, vol. 30, pp. 277-284, 1999. doi:10.1016/S1359-835X(98)00157-2.

[6] L. M. Matuana, J. J. Balatinecz, R. N. S. Sodhi and C. B. Park, "Surface characterization of esterified cellulosic fibers by XPS and FTIR spectroscopy," Wood Sci. and Technol., vol. 35, pp. 191-201, 2001. doi:10.1007/s002260100097.

[7] Y. Li, Y.-W. Mai and L. Ye, "Sisal fibre and its composites: a review of recent developments," Compos. Sci. Technol., vol. 60, pp. $2037-$ 2055, 2000. doi:10.1016/S0266-3538(00)00101-9.

[8] I. V. d. Weyenberg, J. Ivens, A. D. Coster, B. Kino, E. Baetens and I. Verpoesta, "Influence of processing and chemical treatment of flax fibres on their composites," Compos. Sci. Technol., vol. 63, pp. 12411246, 2003. doi:10.1016/S0266-3538(03)00093-9.
[9] M. Baiardo, E. Zini and M. Scandola, "Flax fibre-polyester composites," Compos. Part A: Appl. Sci. and Manuf., vol. 35, pp. 703710, 2004. doi:10.1016/j.compositesa.2004.02.004.

[10] D. Stokke , M. Kuo , D. Curry and H. Giseslman , "Grassland flour/polyethylene composites," in Proceedings of IWPC-6 conf., Madison, USA, 2001.

[11] J. Murphy, Reinforced plastics handbook, 2nd ed., Elsevier Advanced Technology, 1998.

[12] S. Sultana, M. M. Huque and M. M. Helali, "Studies on the Physicomechanical Properties of Sodium Periodate Oxidized Jute Reinforced Polypropylene (PP) Composites," Polymer-Plastics Technology and Engineering, vol. 46, p. 385-391, 2007. doi:10.1080/03602550601156045.

[13] M. J. Folkes, Short fiber reinforced thermoplastics composites, Wiley, New York, 1982.

[14] R. P. Sheldon, Composite polymeric materials, Applied Science Publishers, London, 1982

[15] A, Kelly and N. H. Macmillan, Strong solids, Oxford: Clarendon Press, 1986.

[16] W. Brostow and R. D. Corneliussen, Failure of plastics, New York: Hanser, 1986.

[17] D. Hull, An introduction to composite materials, London: Cambridge University Press, 1981.

[18] L. J. Broutman and R. H. Krock, Modern Composite Materials, Addison Wesley, Reading, MA, 1967.

[19] J. C. Halpin and J. L. Kardos, "The Halpin-Tsai equations: a review", Polym. Eng. Sci., vol. 16, pp. 344-52, 1976. doi:10.1002/pen.760160512.

[20] W. H. Bowyer and M. G. Bader, "On the re-inforcement of thermoplastics by imperfectly aligned discontinuous fibers", J. Mater. Sci., vol. 7, pp. 1315-1321, 1972. doi:10.1007/BF00550698.

[21] C. K. Hong, "Mechanical properties of silanized jute-polypropylene composites", J. Indus. Eng. Chem., vol. 14, pp. 71-76, January 2008. doi:10.1016/j.jiec.2007.07.002.

[22] Sk. S. Chestee, "Short jute fiber reinforced polypropylene composites: effect of nonhalogenated fire retardants." Adv. in Chem., pp. 1-8, 2017. doi: $10.1155 / 2017 / 1049513$

[23] Md. R. Rahman, Md. M. Huque, Md. N. Islam, M. Hasan, "Improvement of physico-mechanical properties of jute fiber reinforced polypropylene composites by post-treatment", Compos. Part A: Appl. Sci. and Manuf., vol. 39, pp. 1739-1747, 2008. doi:10.1016/j.compositesa.2008.08.002.

[24] S. Sultana, M. M. Huque and M. M. Helali, "Studies on the physicomechanical properties of sodium periodate oxidized jute reinforced polypropylene (PP) composites", Ploym. -Plast. Technol. Eng., vol. 46, pp. 385-391, 2007. doi:10.1080/03602550601156045.

[25] G. Kalaprasad, K. Joseph and S. Thomas, "Theoretical modelling of tensile properties of short sisal fibre-reinforced low-density polyethylene composites", J. Mater. Sci., vol 32, pp. 4261-4267, 1997. doi:10.1023/A:1018651218515. 